\title{
AN OBSERVATIONAL STUDY OF THE MESOSCALE MISTRAL DYNAMICS
}

\author{
VINCENT GUENARD ${ }^{1, *}$, PHILIPPE DROBINSKI ${ }^{2}$, JEAN-LUC CACCIA $^{3}$, \\ BERNARD CAMPISTRON ${ }^{4}$ and BRUNO BENECH ${ }^{4}$ \\ ${ }^{1}$ LSEET-LEPI, CNRS, Université Sud Toulon-Var, La Garde, France; ${ }^{2} S A, C N R S$, Institut \\ Pierre Simon Laplace, Paris, France; ${ }^{3}$ LSEET-LEPI, CNRS, Université Sud Toulon-Var, La \\ Garde, France; ${ }^{4} L A, C N R S$, Observatoire Midi-Pyrénées, Université Paul Sabatier,
}

Campistrous, France

\begin{abstract}
We investigate the mesoscale dynamics of the mistral through the wind profiler observations of the MAP (autumn 1999) and ESCOMPTE (summer 2001) field campaigns. We show that the mistral wind field can dramatically change on a time scale less than 3 hours. Transitions from a deep to a shallow mistral are often observed at any season when the lower layers are stable. The variability, mainly attributed in summer to the mistral/land-sea breeze interactions on a 10-km scale, is highlighted by observations from the wind profiler network set up during ESCOMPTE. The interpretations of the dynamical mistral structure are performed through comparisons with existing basic theories. The linear theory of R. B. Smith [Advances in Geophysics, Vol. 31, 1989, Academic Press, 1-41] and the shallow water theory [Schär, C. and Smith, R. B.: 1993a, J. Atmos. Sci. 50, 1373-1400] give some complementary explanations for the deep-to-shallow transition especially for the MAP mistral event. The wave breaking process induces a low-level jet (LLJ) downstream of the Alps that degenerates into a mountain wake, which in turn provokes the cessation of the mistral downstream of the Alps. Both theories indicate that the flow splits around the Alps and results in a persistent LLJ at the exit of the Rhône valley. The LLJ is strengthened by the channelling effect of the Rhône valley that is more efficient for north-easterly than northerly upstream winds despite the north-south valley axis. Summer moderate and weak mistral episodes are influenced by landsea breezes and convection over land that induce a very complex interaction that cannot be accurately described by the previous theories.
\end{abstract}

Keywords: Atmospheric boundary layer, Gap flow, Linear theory, Mistral, Shallow water theory, UHF wind profiler.

\section{Introduction}

The mistral is a northerly, low-level, orography-induced, cold-air outbreak over the north-western Mediterranean. It accompanies cold and dry continental air masses and restores clear sky conditions after the passage of a cold front over Provence (south-eastern France). During summer, it accelerates ground drying and is responsible for the propagation of devastating forest fires (Wrathall, 1985). Furthermore, mistral gusts can cause severe damage to

*E-mail: guenard@1seet.univ-tln.fr 
farm plantations, hazardous conditions for aviation and ship navigation (Mayençon, 1982) and increased forest fire risks. It is frequently observed to extend as far as a few hundred kilometres from the coast. Its thermodynamics favour intense air-sea exchange (Flamant, 2003). It lowers the sea surface temperature (Millot, 1979) and forms the western Mediterranean deep water that moves into the Atlantic Ocean (Rhein, 1995). It also affects the dilution of pollutant species released by industrial plants located along the Rhône valley and near Marseille (Corsmeier et al., 2004).

North-westerly to north-easterly flows that impinge on the Alpine range are dynamically blocked by the ridge and a lee cyclone develops in the Gulf of Genoa. The resulting flow is substantially accelerated in the Rhône valley that separates the French Alps (highest elevation, $4807 \mathrm{~m}$ ) from the Massif Central (highest elevation, $1885 \mathrm{~m}$ ) by a gap $200 \mathrm{~km}$ long and $60 \mathrm{~km}$ wide (Figure 1). The flow in the southern part of the Rhône is referred as the mistral.

The dynamics have been first described by reduced-gravity shallow-water theory (RGSWT), in which the flow is bounded by a free surface (Pettré, 1982). This hydraulic analogy is the oldest conceptual model and was proposed by Long (1953). Durran (1986) suggested that there is a fundamental similarity between downslope windstorms and hydraulic jumps. In the case of the mistral, the two-dimensional flow treated in the RGSWT is not realistic since three-dimensional processes play a major role in the splitting around

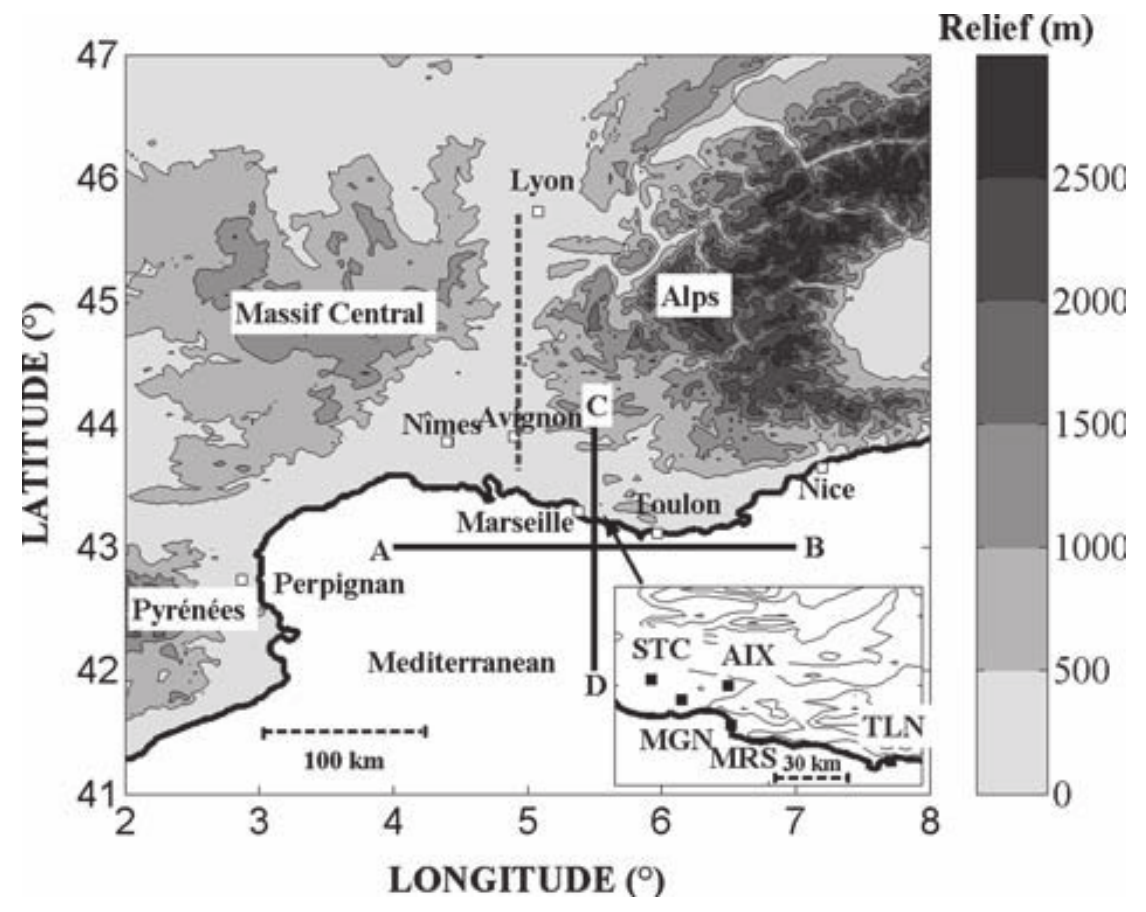

Figure 1. Target area in southern France. The lower-right encapsulated map shows the UHF-radar network deployed during ESCOMPTE around Marseille, except for TLN, used only for MAP. The acronyms are listed in Table II. Geostrophic winds given in Table I are computed from the ECMWF analysis along the transects AB and CD. The dashed line in grey indicates the Rhone valley axis. 
obstacles (Schär and Smith, 1993). From upstream conditions taken at Lyon (see Figure 1), Pettré (1982) gives a description of mistral behaviour arguing that the horizontal distribution is closely linked with hydraulic jumps. In downslope windstorms, Smith $(1985,1989)$ found that wave breaking is associated with hydraulic jumps and in turn associated with the generation of potential vorticity (Smolarkievicz and Rotunno, 1993; Schär and Smith, 1993). Drobinski et al. (2001a) have shown that the location at which a hydraulic jump occurs depends on the upstream and downstream flow conditions and not only from upstream conditions. Recent high resolution simulations have shown that the western and eastern boundaries of the mistral are partly defined by gravity wave breaking over the Massif Central and the Alps, respectively (Jiang et al., 2003). Recently, P. Drobinski et al. (2004, private communication) have found that additional processes such as wall separation on the western flanks of the southern Alps are involved in the Alps wake formation. As suggested by Jiang et al. (2003), the Massif Central wake separates the mistral from the tramontane. The latter flow blows between the Massif Central and the Pyrénées and is considered as the companion of the mistral since they have the same synoptic origin and often blow simultaneously (Georgelin and Richard, 1996; Drobinski et al., 2001b).

Although the large-scale features of the mistral are well described, mesoscale aspects such as the temporal, vertical and horizontal variability, its onset and cessation are still to be investigated. During MAP (Mesoscale Alpine Program, autumn 1999, see Bougeault et al., 2001) and ESCOMPTE (Expérience sur Site pour Contraindre les Modèles de Pollution atmosphériques et de Transport d'Emissions, summer 2001, see Cros et al., 2004) field experiments, a UHF wind profiler network was deployed in Provence, near the coast, to document the spatial and temporal structure of the flow. The network approach combined with high vertical and time resolutions of the UHF-wind profilers enables the study of the inhomogeneity and unsteadiness of the mistral as well as mistral-atmospheric boundary-layer (ABL) interactions.

In this paper, seven cases of mistral documented by UHF wind profilers are reported: three during MAP, in autumn, and four during ESCOMPTE, in summer. Bordreuil et al. (1973) have shown that the mistral exhibits a seasonal variability on either speed or direction. In cold seasons, the mean mistral is featured by strong northerly wind that can persist over one week and often reach 15-20 $\mathrm{m} \mathrm{s}^{-1}$ at coastal ground stations. In warm seasons, the mean mistral is weaker (from 5 to $10 \mathrm{~m} \mathrm{~s}^{-1}$ ). Its zonal component prevails but rarely persists more than three consecutive days.

The seven mistral events are used to: (i) study the mechanisms responsible for the spatial and temporal variability, sometimes very fast, of the vertical structure, and (ii) investigate the mechanisms that can explain the seasonal variability of mistral characteristics. 


\section{Synoptic Environment of the Mistral}

The synoptic environment for the mistral is well illustrated by the meteorological situation of the MAP IOP 15 during 06-08 November 1999. It is characterized by the passage of a cut-off low over the North Sea that induces a north-westerly flow impinging on the Alps range (Figure 2a). Genoa cyclogenesis is then triggered in two phases (Egger, 1972; Buzzi and Tibaldi, 1978; Bleck and Mattocks, 1984). The first phase (Figure 2a) is associated with retardation of the cold front associated with the deep cyclone over the North Sea, and the rapid formation of a shallow vortex supplying a low level source of potential vorticity at the south-western edge of the Alps (Aebischer and Schär, 1998). During the second phase (Figure 2b), the growth rate drops to baroclinic values as a classical cyclogenesis (Bleck and Mattocks, 1984; Tafferner and Egger, 1990). Surface winds strengthen and veer
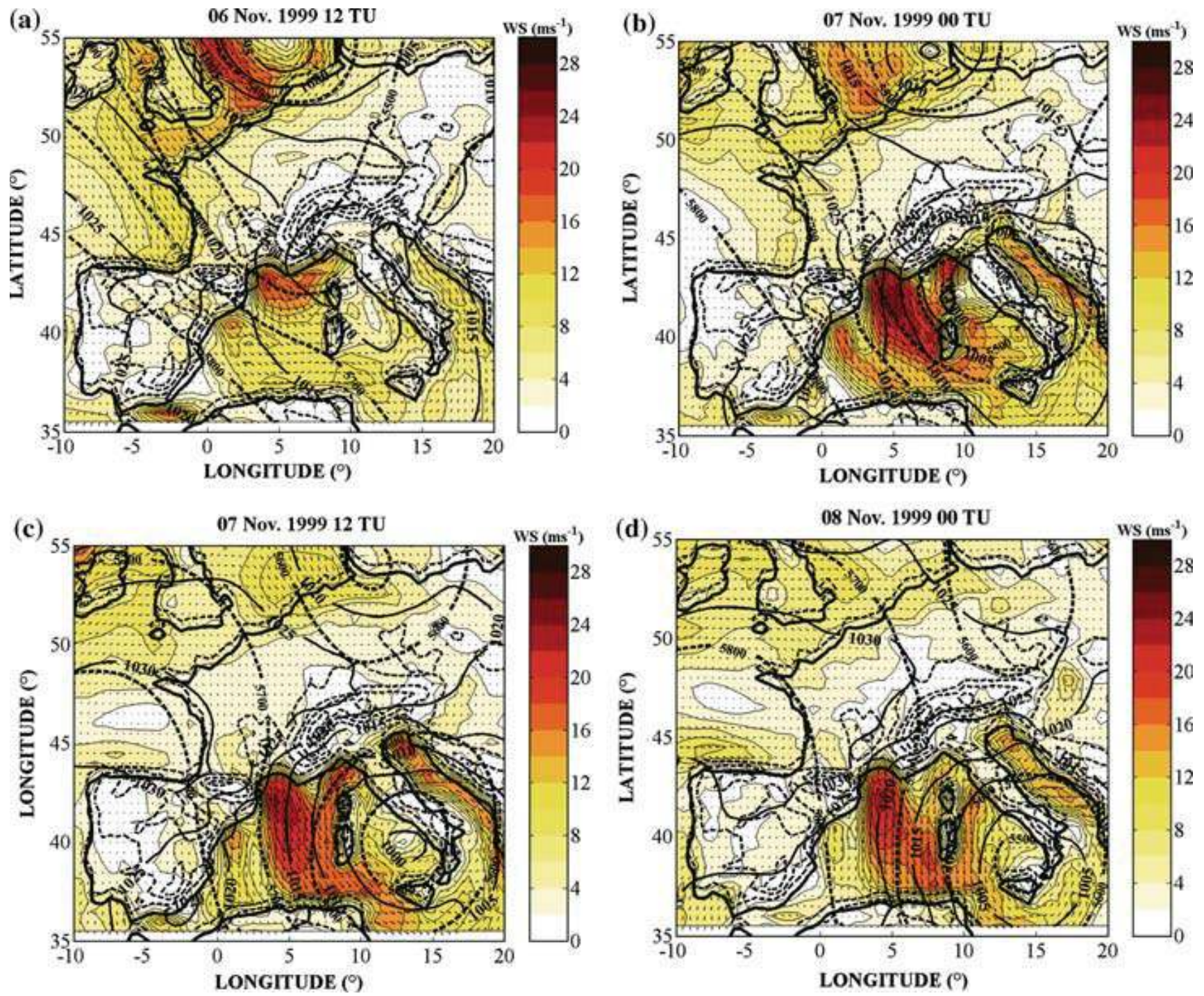

Figure 2. ECMWF analyses from the 06 November 19991200 UTC (TU) to the 08 November 199900 UTC (given each 12 hours). Surface pressure (hPa) is indicated by sold lines, $500 \mathrm{hPa}$ geopotential height $(\mathrm{m})$ by dashed lines. The coloured scale gives the $1000 \mathrm{hPa}$ horizontal wind speed (WS). Black arrows give the corresponding wind direction. 
south-eastward. The pressure gradient over the Mediterranean increases with the development of the Azores ridge over Spain and western France (Figure 2c) supplying cold and dry air that passes over the Alps. This results in the displacement of the cyclone towards south-eastern Italy (Figure 2d). Then, the pressure gradient vanishes as the cyclone moves farther eastward. Despite a persistent offshore mistral, the onshore winds stop on the 08 November 19991200 UTC.

Table I reports the main features of selected MAP and ESCOMPTE mistral cases. Three mistral events occurred during MAP and four during ESCOMPTE. The $1000 \mathrm{hPa}$ ECMWF (European Centre of Medium-range Weather Forecasts) analyses along the $\mathrm{AB}$ and $\mathrm{CD}$ transects (Figure 1) are used to compute the geostrophic winds from the pressure gradient between the Gulf of Genoa cyclone and the Azores high pressure system. In most mistral events reported in Table I, the configuration of the synoptic environment is the same as described above despite a weaker synoptic forcing. For the weaker case (21-23 June 2001), the cyclogenesis in the southern Alps is a consequence of an interaction between a westerly flow and a overheated land surface with a relative cold sea surface.

In the following, three mistral cases are detailed: the strongest event of the 06-08 November 1999, the moderate event of the 01 July 2001 and the weak event of the 21-23 June 2001.

\section{TABLE I}

Synoptic and dynamic features of the detailed mistral events. Geostrophic winds are computed from the $1000 \mathrm{hPa}$ ECMWF analysis charts along the transects $\mathrm{AB}$ and $\mathrm{CD}$ of Figure 1. The surface winds, from the Météo-France surface network, are the hourly averaged maximum values recorded during the event at Marignane airport (MGN), near Marseille. IOP stands for Intensive Observing Period. WS and WD denote the wind speed in $\mathrm{m} \mathrm{s}^{-1}$ and the wind direction in degree respectively.

\begin{tabular}{|c|c|c|c|c|c|c|}
\hline \multirow[t]{2}{*}{ Experiment } & \multirow[t]{2}{*}{ Date } & \multirow[t]{2}{*}{$\begin{array}{l}\text { Duration } \\
\text { (h) }\end{array}$} & \multicolumn{2}{|c|}{$\begin{array}{l}\text { Geostrophic winds } \\
\text { at } 1000 \mathrm{hPa}\end{array}$} & \multicolumn{2}{|c|}{$\begin{array}{l}\text { MGN maximum } \\
\text { surface winds }\end{array}$} \\
\hline & & & $\mathrm{WS}\left(\mathrm{m} \mathrm{s}^{-1}\right)$ & $\mathrm{WD}\left(^{\circ}\right)$ & $\mathrm{WS}\left(\mathrm{m} \mathrm{s}^{-1}\right)$ & WD $\left(^{\circ}\right)$ \\
\hline MAP & 1999 & & & & & \\
\hline IOP 4 & 01 October & 24 & 25 & 350 & 15 & 340 \\
\hline IOP 5 & 05 October & 24 & 30 & 0 & 14 & 340 \\
\hline IOP 15 & 06-08 November & 43 & 37 & 5 & 20 & 350 \\
\hline \multicolumn{7}{|c|}{ ESCOPMPTE 2001} \\
\hline & 16-18 June & 54 & 26 & 340 & 19 & 340 \\
\hline & 21-23 June & 72 & 12 & 315 & 9 & 270 \\
\hline & 28 June & 24 & 17 & 340 & 14 & 330 \\
\hline & 10 July & 30 & 16 & 10 & 13 & 340 \\
\hline
\end{tabular}




\section{Experimental Set-Up}

The measurements have been made using Degréane UHF wind profilers, and consist of the time evolution of the vertical profiles of the three wind components. They are obtained along a single vertical beam and two, or four (depending upon the radar), oblique beams slanted at an off-zenith angle of $17^{\circ}$ the half-power beam width being $8.5^{\circ}$. The wind profilers work with a frequency of $1238 \mathrm{MHz}(\approx 0.3 \mathrm{~m}$ wavelength), and with a peak power of $4 \mathrm{~kW}$. Returned echoes are due to the air refractive index fluctuations advected by the wind. The wind velocity is estimated from the frequency corresponding to the mean Doppler shift obtained in the radar echo. The data quality control and processing are carried out through a consensus algorithm based on time and height continuity of measured spectra. The consensus works over a 60-min period providing a wind profile each $15 \mathrm{~min}$ from a height of $0.1-0.3 \mathrm{~km}$ AGL up to $2.5-4 \mathrm{~km}$ AGL (depths probed by UHF wind profilers are indicative since they are sensitive to meteorological parameters such as humidity). The vertical resolution is typically $75-150 \mathrm{~m}$. The errors in the horizontal (vertical) wind measurements are typically $1-2 \mathrm{~m} \mathrm{~s}^{-1}\left(0.25-0.5 \mathrm{~m} \mathrm{~s}^{-1}\right)$. Table II summarizes the location of the wind profilers during MAP and ESCOMPTE experiments.

During MAP, two UHF wind profilers have been set up near Marseille, at St Chamas (STC), and Toulon (TLN), $90 \mathrm{~km}$ apart (see Figure 1 for the exact location of STC and TLN). Both wind profilers were near the shore, TLN being located in an urban area and STC in the countryside. During ESCOMPTE, the STC wind profiler was still available, the MGN radar was located closer to the sea, the MRS radar at Marseille in an urban area and the AIX radar at Aix les Milles in a military airport. On average, those radars

TABLE II

Site locations of UHF wind profilers set up during the MAP and ESCOMPTE experiments.

\begin{tabular}{llllll}
\hline Experiment & Institute name & Site & Acronyms & $\begin{array}{l}\text { Longitude } \\
\left({ }^{\circ} \mathrm{E}\right)\end{array}$ & $\begin{array}{l}\text { Latitude } \\
\left({ }^{\circ} \mathrm{N}\right)\end{array}$ \\
\hline MAP & EDF and & ST CHAMAS & STC & 5.12 & 43.53 \\
ESCOMPTE & LA/OMP & & & & \\
MAP & Degréane & TOULAN & TLN & 5.97 & 43.12 \\
ESCOMPTE & Degréane & AIX LES & AIX & 5.37 & 43.50 \\
& & MILLES & & & \\
ESCOMPTE & Météo-France & MARIGNANE & MGN & 5.22 & 43.43 \\
ESCOMPTE & CNRM/ & MARSILLE & MRS & 5.38 & 43.30 \\
& Météo-France & & & & \\
\hline
\end{tabular}


were installed $30 \mathrm{~km}$ apart. During each experiment, routine radio soundings were launched at Nîmes and Lyon by Météo-France (Figure 1) each six hours in the MAP experiment (each three hours on the 06 November 1999) and each 12 hours in the ESCOMPTE framework. This whole experimental network, i.e. wind profilers and radio soundings, allows a novel mesoscale investigation.

\section{The Wind Profilers Observations}

\subsection{The Severe Autumn mistral episode (6-8 November 1999)}

Time-height cross-sections of the horizontal wind speed and direction, above STC and TLN are presented in Figures $3 \mathrm{a}, 3 \mathrm{~b}$ respectively. The strong wind events, defined by the time-height region where the wind speed is stronger than $15 \mathrm{~m} \mathrm{~s}^{-1}$, may be divided in three successive phases.

On 06 November 1999 from 1200 to 1400 UTC, the mistral starts blowing from the north-west at STC and from the west at TLN between 15 and $25 \mathrm{~m} \mathrm{~s}^{-1}$ above $1 \mathrm{~km} \mathrm{AGL}$. Between 06 November 1999 at 1400 UTC and 07 November 1999 at 0400 UTC at STC, the wind increases up to $25-35 \mathrm{~m} \mathrm{~s}^{-1}$ and veers to the north/north-west up to the upper range of the UHF measurements. Above TLN, the wind increases on 06 November 1999 between 1400 and 2100 UTC but remains slightly weaker than above STC (i.e. between 25 and $30 \mathrm{~m} \mathrm{~s}^{-1}$ ) and veers to the west/north-west up to the UHF radar detection limit. The difference in wind direction, which is more eastward at TLN than at STC, is a classical mistral feature.

Between 07 November 1999 at 0400 UTC and 08 November 1999 at 0900 UTC at STC, and between 06 November 1999 at 2100 UTC and 07 November 1999 at 0600 UTC at TLN, strong northerly winds are found below $1 \mathrm{~km}$ AGL with a low-level jet structure (LLJ). The wind speed maxima, found around $0.5 \mathrm{~km} \mathrm{AGL}$, progressively decrease from 30 to less than $15 \mathrm{~m} \mathrm{~s}^{-1}$. One noticeable difference between the two sites is that the mistral event ends seven hours earlier at TLN than at STC.

4.2. The WeAK AND MOderate SUMmer Mistral ePisodes (21-23 June AND 01 JULY 2001)

During ESCOMPTE, two interesting mistral events have been documented by the UHF wind profilers listed in Table II: a weak mistral from 21 to 23 June 2001 and a moderate mistral from 30 June to 1 July 2001. Unfortunately, the UHF wind profiler located at TLN was not operated during ESCOMPTE so the spatial variability of the mistral flow is addressed on a 

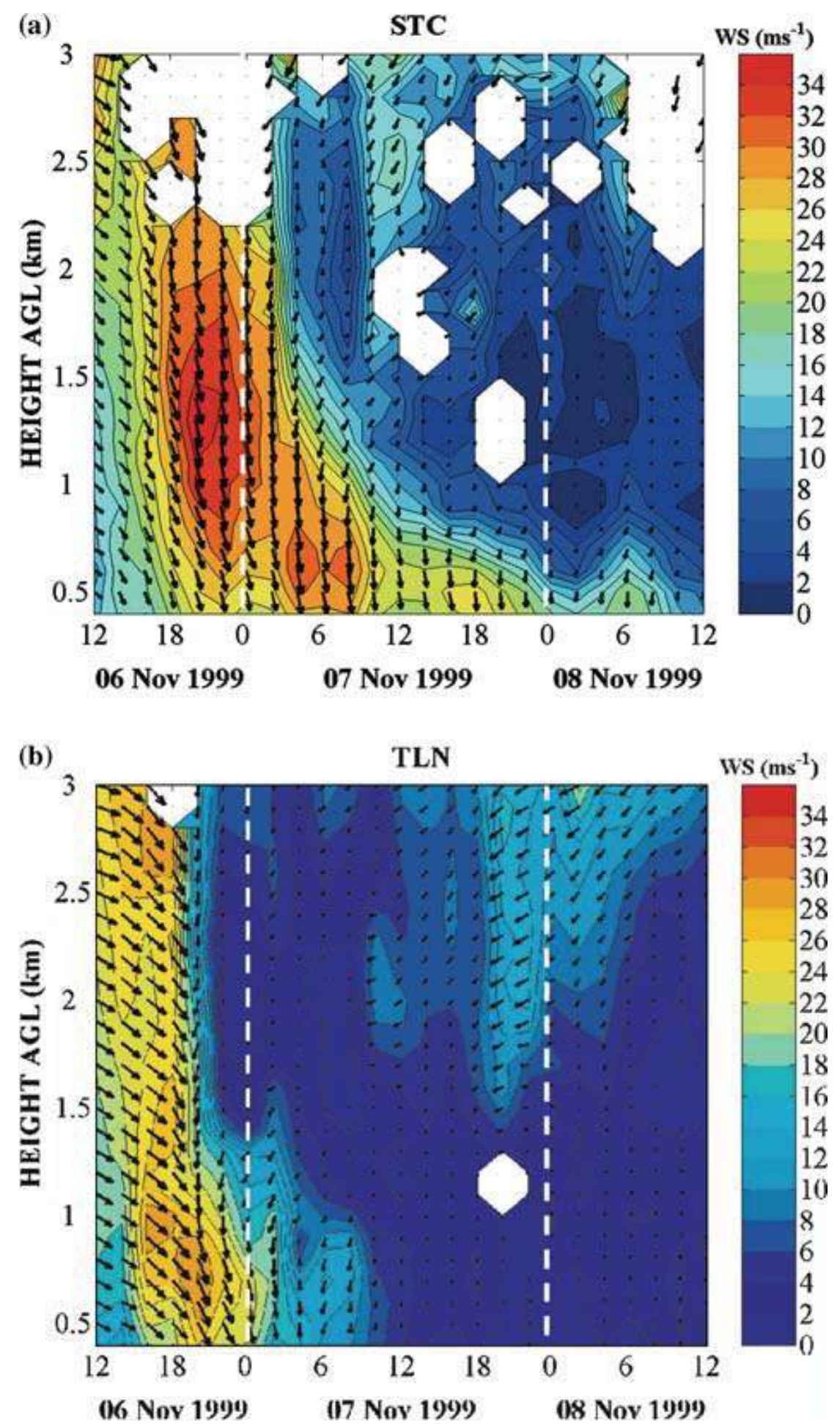

Figure 3. Time-height diagrams of the horizontal wind given by the (a) STC and (b) TLN wind profilers from the 06 to 08 November 19991200 UTC. The wind speed $\left(\mathrm{m} \mathrm{s}^{-1}\right)$ is given by the coloured scale. Black arrows are the horizontal wind vectors.

spatial scale of $30 \mathrm{~km}$. Table I indicates that these events are characterised by a weaker pressure gradient than during the MAP IOP 15 event, leading to substantially weaker winds as displayed in Figures 4 and 5 which show time-height cross-sections of the horizontal wind strength and direction measured by the AIX and STC UHF-wind profilers from 21 to 23 June 2001 and from 30 June to 1 July 2001, respectively.

The highest wind speeds recorded during the 21 to 23 June 2001 event, were in the $12-15 \mathrm{~m} \mathrm{~s}^{-1}$ range, below $1.5 \mathrm{~km} \mathrm{AGL} \mathrm{(Figure} \mathrm{4).} \mathrm{One} \mathrm{striking}$ 

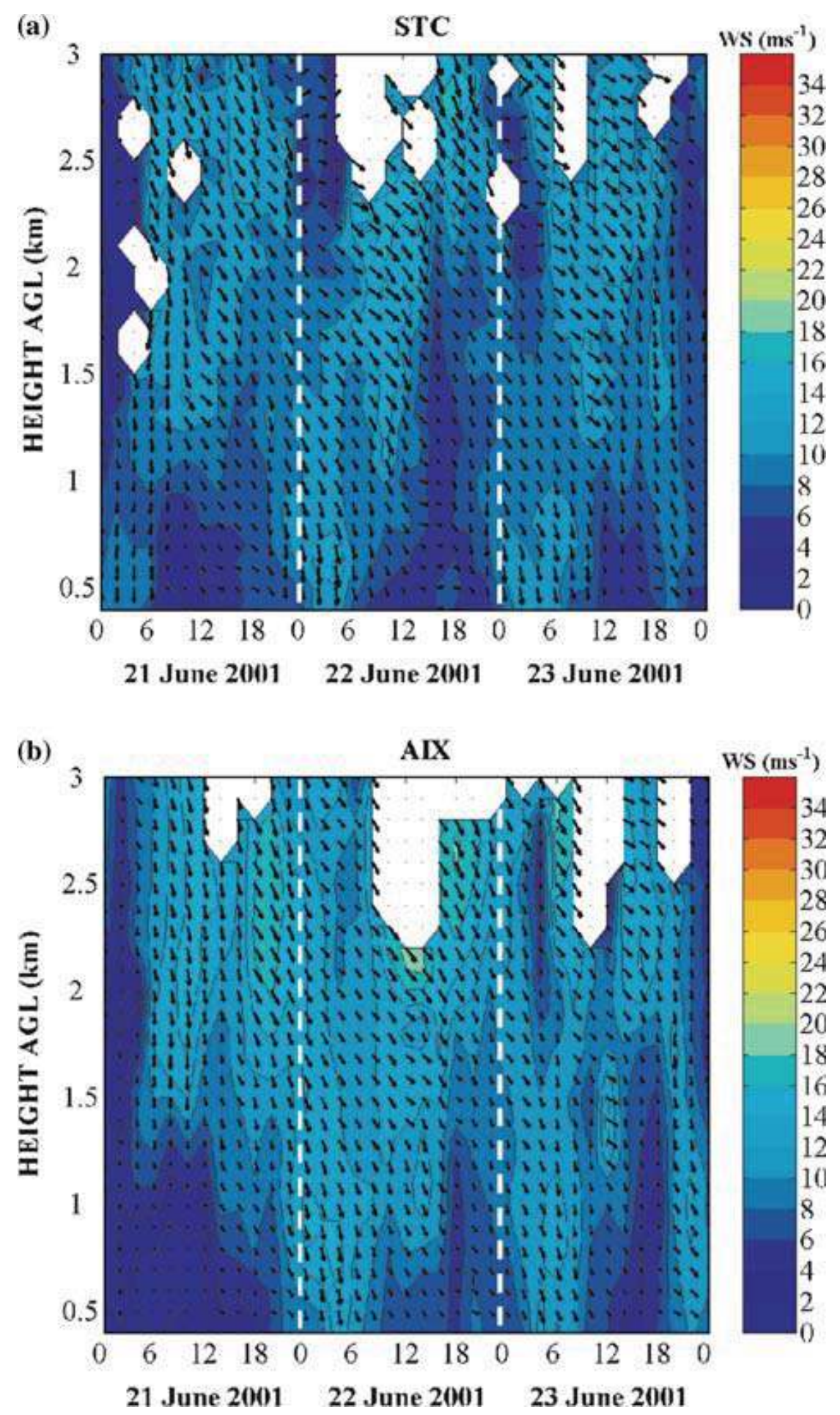

Figure 4. Time-height diagrams of the horizontal wind given by the (a) STC and (b) AIX wind profilers from the 21 to 24 June 20010000 UTC. The wind speed $\left(\mathrm{m} \mathrm{s}^{-1}\right)$ is given by the coloured scale. Black arrows are the horizontal wind vectors.

feature is that the mistral is embedded in a $1.5-\mathrm{km}$ deep layer at night between 2200 and 0900 UTC, with maximum wind speed between 0200 and 0600 UTC, whereas during the afternoon, it is 'lifted up' above $1.5 \mathrm{~km} \mathrm{AGL}$, as the near-surface wind, i.e. below $1.5 \mathrm{~km}$ AGL, decreases down to $\approx 5 \mathrm{~m} \mathrm{~s}^{-1}$, and veers to the west. This behaviour is systematically observed above the two radar sites during the three days of the event.

For the moderate event (Figure 5), the mistral starts blowing on the 30 June 2001 afternoon with maximum wind speed ranging from 15 to $18 \mathrm{~m} \mathrm{~s}^{-1}$ 

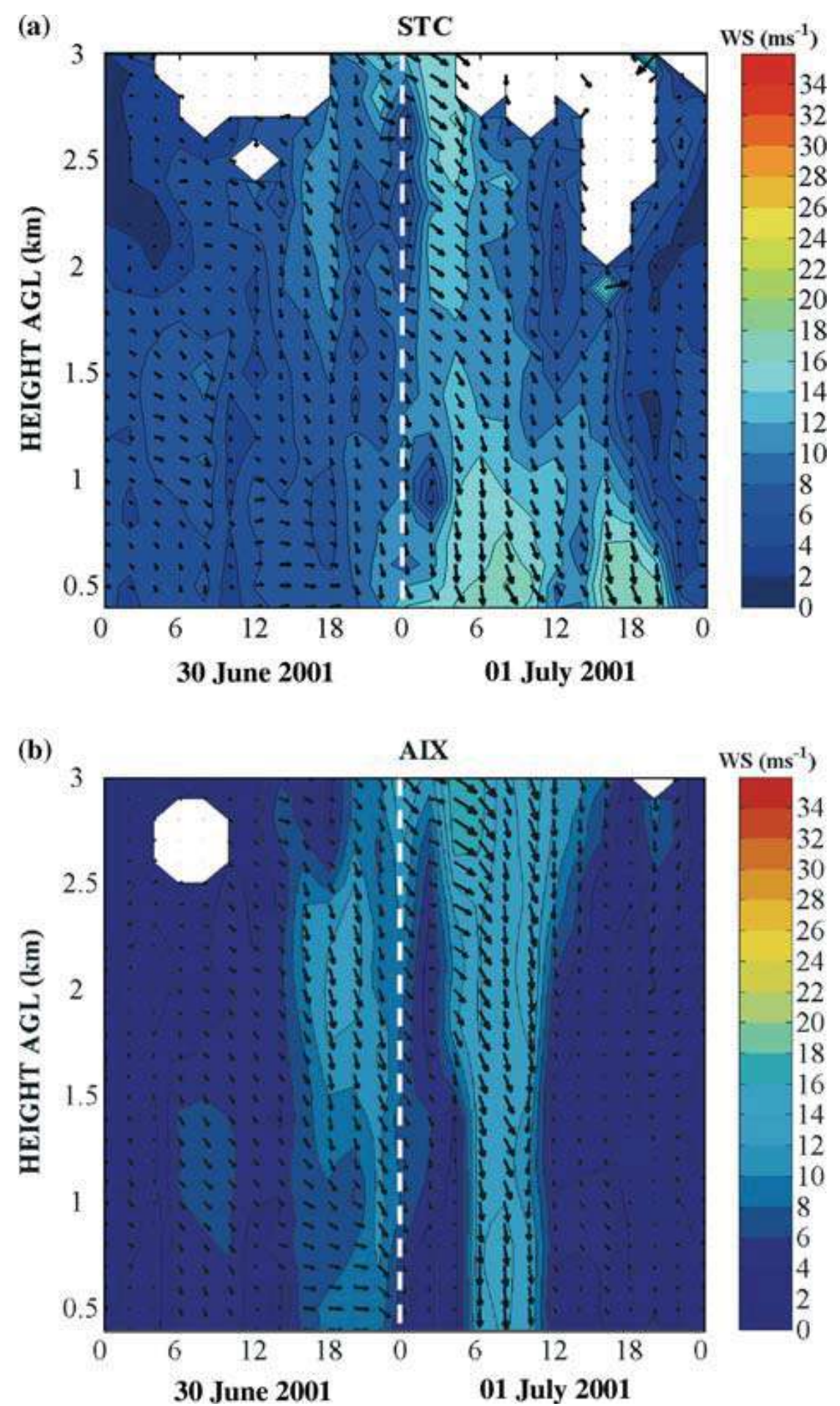

Figure 5. Same as Figure 4 from 30 June 2001 to 02 July 20010000 UTC.

between 1.5 and $2.5 \mathrm{~km}$ AGL above the two sites. During the onset phase and similar to the 21 to 23 June 2001 event, weak westerly winds (i.e between 2 and $10 \mathrm{~m} \mathrm{~s}^{-1}$ ) blow up to $1 \mathrm{~km} \mathrm{AGL}$. Although the time series of the vertical profiles of wind direction profiles are quite similar at AIX and STC, the time series of the vertical profiles of wind speed differ between AIX and STC despite the proximity of the radars (here installed $25 \mathrm{~km}$ apart). At STC, as opposed to AIX, the mistral flow is embedded in a $1.5-\mathrm{km}$ deep layer. This suggests that the local structure of the mistral may be combined with small-scale local winds because of the close-by topography and the proximity 
of the sea. It should also be noticed that the near-surface weak westerly wind is not observed during the afternoon on the 01 July 2001.

\section{Discussion}

The purpose of this section consists in interpreting the mistral observations obtained with the wind profilers. The discussion especially focuses on the transition between the deep and shallow mistral during the severe event (0608 November 1999) and the interactions of the mistral with land-sea breezes during less marked episodes (21-23 June and 01 July 2001).

\subsection{The Autumn mistral}

During the 06-08 November 1999 mistral event, the synoptic forcing is well marked so that the whole Alps ridge is affected by the northerly flows. The linear theory (Smith, 1989) and the RGSW theory (Schär and Smith, 1993) can be used to interpret the UHF wind observations. The incident conditions are defined by the vertical soundings at Lyon (Pettré, 1982). Figure 6 display the horizontal wind (Figure 6a) and the isentropes (Figure 6c) interpolated from the radiosonde data at Lyon. The same presentation is made on the radiosonde data at Nîmes, located in the southern Rhône valley (Figure 6b and $6 \mathrm{~d})$.

The analysis of the flow upstream the Massif Central and the Alps (Figure 6a) clearly shows weaker winds $\left(10-20 \mathrm{~m} \mathrm{~s}^{-1}\right.$ range below $3 \mathrm{~km}$ AGL) and suggests a blocking process. Furthermore, a substantial shift in the orientation of the winds occurs. On 06 November 1999 between 1200 and 1800 UTC, upstream conditions are marked by north-westerly flows that blow below $15 \mathrm{~m} \mathrm{~s}^{-1}$. From 06 November 1999 at 1800 UTC to the 07 November 1999 at 0000 UTC, northerly flows prevail. Afterwards northeasterly flows affected the mountain ranges.

The analysis of the Nîmes sounding (Figure 6b) shows that the transition between the deep and shallow structure occurs farther westward than STC and confirms that it is not a local feature (see Figure 1). The soundings allow us to better appreciate the vertical structure of the mistral that is limited to $3 \mathrm{~km} \mathrm{AGL}$ in the wind profiler time series. The setting up of the low-level mistral is associated with a decoupling in the dynamics of the lower and upper troposphere. The wind speed magnitude reported at Nîmes is similar than those observed by the two wind profilers (in the $20-30 \mathrm{~m} \mathrm{~s}^{-1}$ range). Unfortunately, the wind cessation at Nîmes is not part of the available observations.

The analysis of the isentropes (Figures $6 \mathrm{c}$ and $6 \mathrm{~d}$ ) shows that the mistral is associated with a well-mixed layer topped by a very stable layer. The thermal 

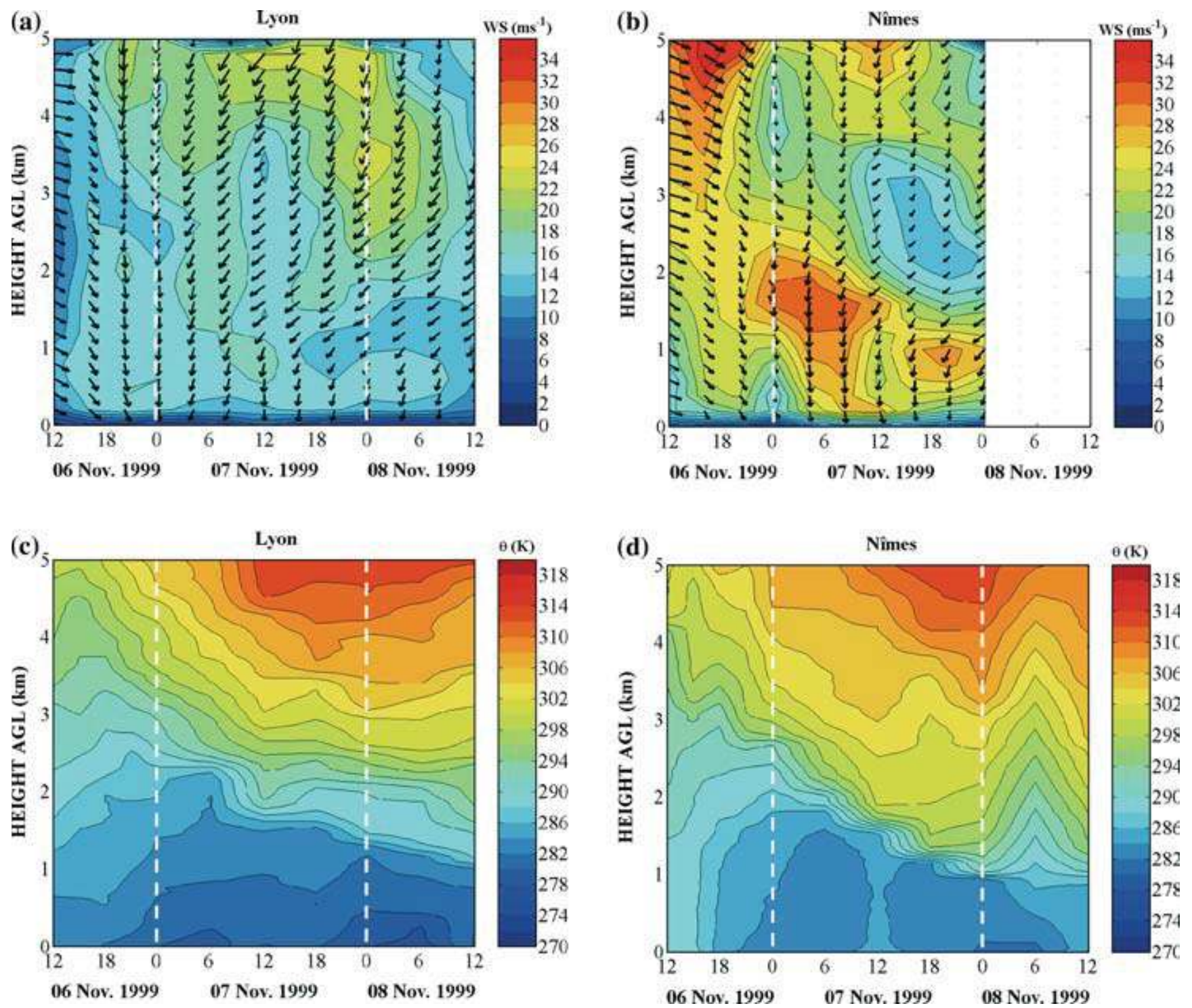

Figure 6. Time-height diagrams from the Lyon and Nîmes radiosonde data interpolated from the 06 to 08 November 19991200 UTC. Horizontal wind ( $\mathrm{m} \mathrm{s}^{-1}$ ) at (a) Lyon and (b) Nîmes. Isentropes (K) at (c) Lyon and (d) Nîmes. The wind speed and the isentropes are given by the coloured scale. Black arrows are the horizontal wind vectors.

inversion, that corresponds with the maximum vertical isentropic gradient, progressively descends throughout the episode as the mistral depth (Figure $6 \mathrm{~d})$.

In the linear theory (Smith, 1989), two parameters control the flow:

- the horizontal aspect ratio of the obstacle $r=a_{\mathrm{y}} / a_{\mathrm{x}}$ where $a_{\mathrm{y}}$ (or $a_{\mathrm{x}}$ ) is the horizontal dimension of the obstacle in a direction perpendicular (or parallel) to the flow.

- the dimensionless mountain height $\hat{h}=N h / U$ where $N$ is the buoyancy frequency, $h$ is the maximum mountain height and $U$ is the incident wind speed.

The values taken by the parameters $(r, \hat{h})$ allows the building of the Smith regime diagram for the linear theory. It predicts the occurrence of mountain 
waves (MW), wave breakings (WB) and flow splitting (FS) in a flow past an obstacle. WB is featured by a stagnation point aloft of the obstacle. When the flow splits around an obstacle, the stagnation point occurs on the windward slope. The linear theory also predicts that a mixture of FS and WB is possible.

From the incident wind orientation, different obstacles are encountered by the air masses. Figure 7 displays the upstream topography at STC (Figure 7a) and TLN (Figure 7b) for north-westerly, northerly and north-easterly incident flows. In north-westerly flows, STC and TLN are affected by the Massif Central. For northerly and north-easterly flows, the Alps plays a major role at the two sites. However, the mountain height varies from one site to the other. The values of $h$ are reported in Table III.

The computation of $r$ is based on the map displayed in Figure $8 \mathrm{a}$ that indicates the dimensions of the Massif Central and the Alps. The $r$ values are also given in Table III. Figure $8 \mathrm{~b}$ reports the linear regime of the flow at STC and TLN.

From the 06 November 19991200 UTC to 1800 UTC, the flow regime is similar at STC and TLN since both influenced by the Massif Central. The linear theory predicts a MW regime. UHF observations indicate a deep mistral and confirm the similar wind structure above the two sites.

From 06 November at 1800 UTC to 07 November at 0000 UTC, the linear theory predicts MW at STC and the coexistence of WB and FS at TLN. WB in downslope windstorms triggers LLJ windstorms as described by Smith (1985). The earlier setting of the TLN LLJ is thus predicted by the linear theory. From the 07 November 0000 UTC to the 08 November 19991200 UTC, the linear theory predicts a FS regime at STC while the conditions are favourable for MW at TLN. The FS encourages the channelling effects within the Rhône valley that triggers the LLJ at STC. Thus, the STC LLJ has not the same origin as the TLN one. At TLN, the MW are difficult to interpret and limit the validity of the linear theory.

After 07 November 1999, three-dimensional processes such as FS play a major role in the flow. Three-dimensional flows are well described by the shallow water theory in case of two-layered flows. Table IV gives the intensity of the thermal inversion computed at Lyon that separates the well-mixed layer of the mistral from a very stable layer aloft (see Figure 6). The thermal inversion strength progressively increases from the beginning of the mistral to the 07 November 19990000 UTC and range from 20 to $30 \mathrm{~K} \mathrm{~km}^{-1}$ for the shallow mistral. Pettré (1982) uses the RGSW theory with thermal inversion strength greater than $15 \mathrm{~K} \mathrm{~km}^{-1}$. The shallow water theory can be thus applied from the 07 November 19990000 UTC and completes the description of the linear theory.

In the shallow water theory (Schär and Smith, 1993), the control parameters are: 

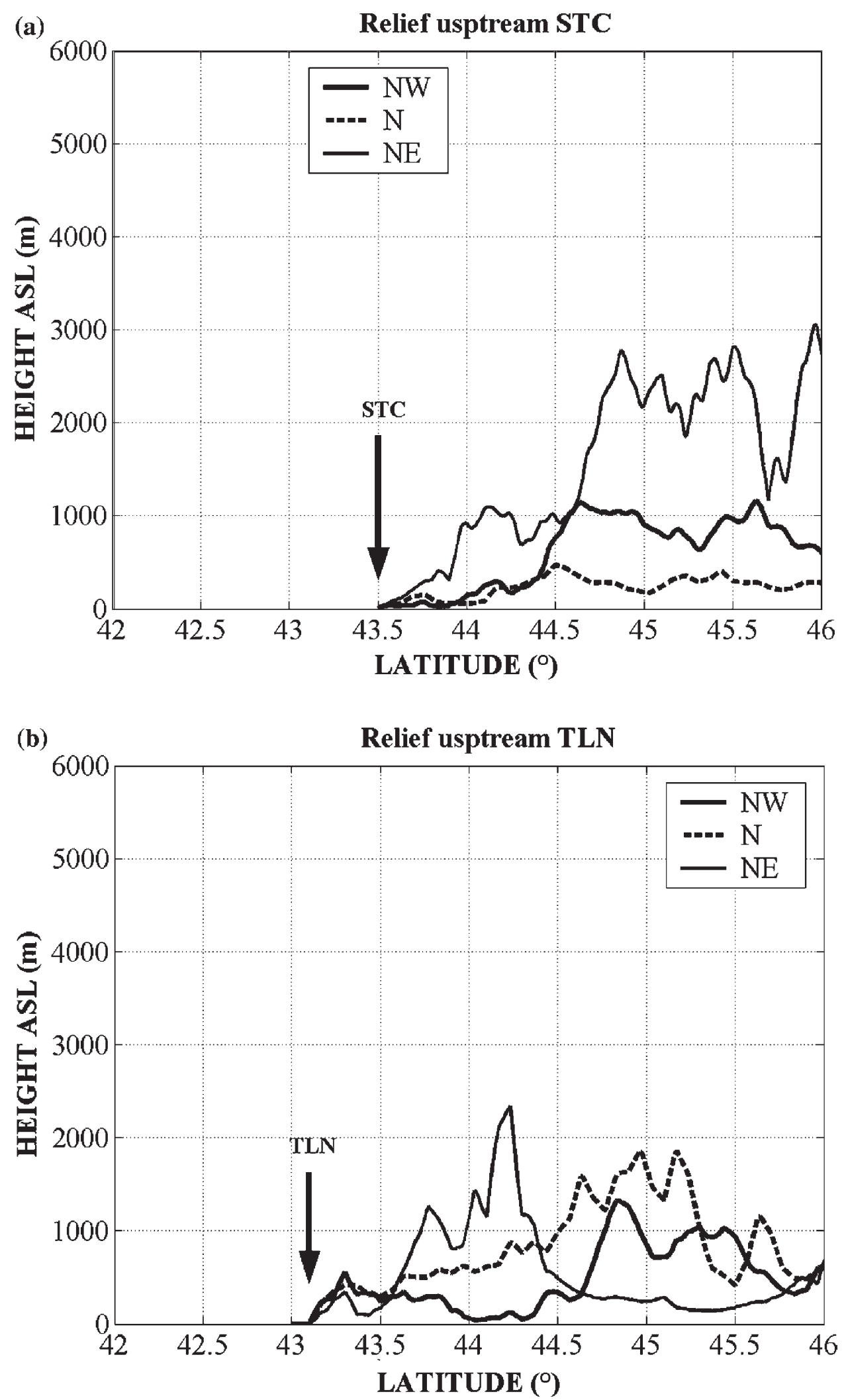

Figure 7. Contours of the mountain crests upstream (a) STC and (b) TLN for the northwesterly (bold line), northerly (dashed line) and north-easterly (solid line) incident flows. The locations of the wind profilers are indicated by the black arrows. These plots define the maximum heights $h$ of the obstacle of the linear theory.

- the non dimensional mountain height $M=h / H$ where $h$ is the maximum mountain height and $H$ is the depth of the well-mixed layer of the mistral. 


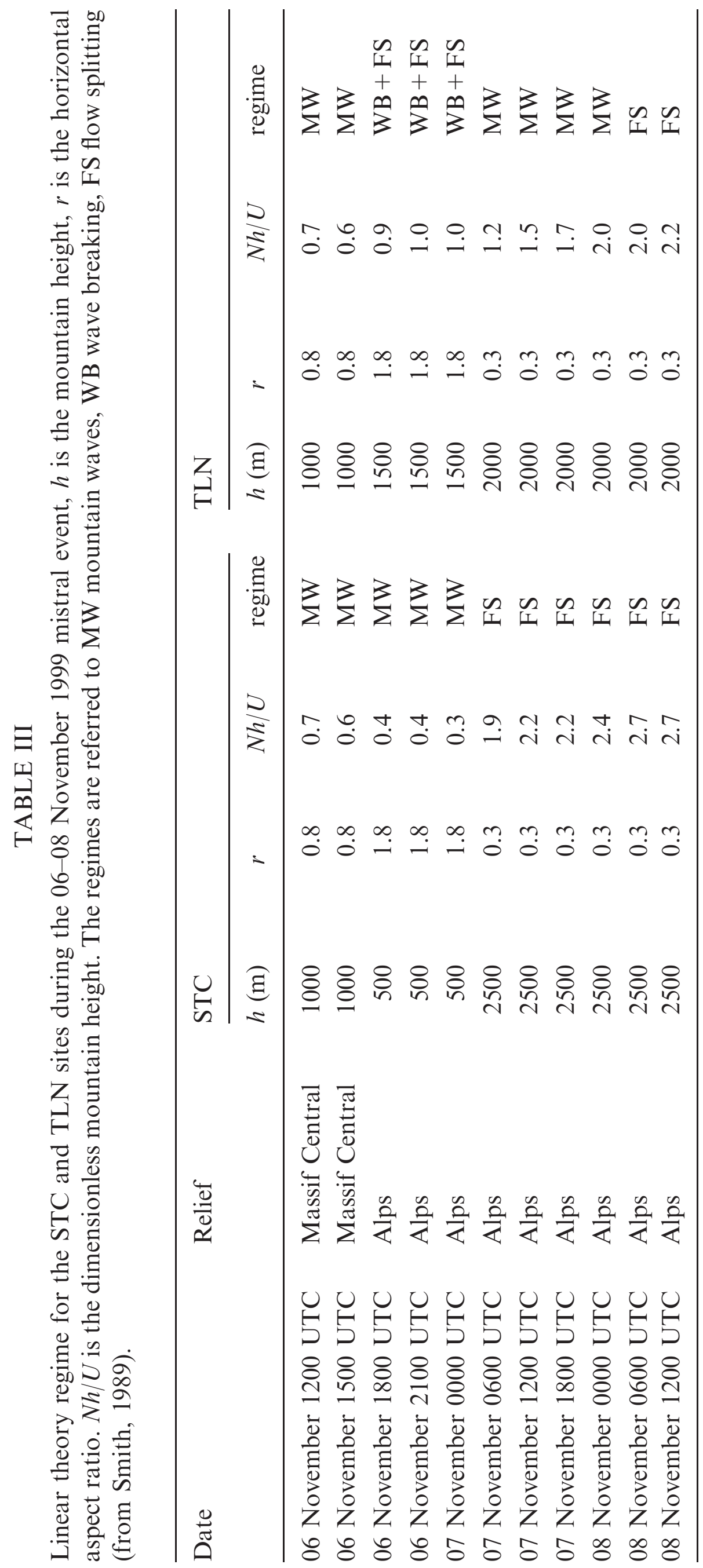



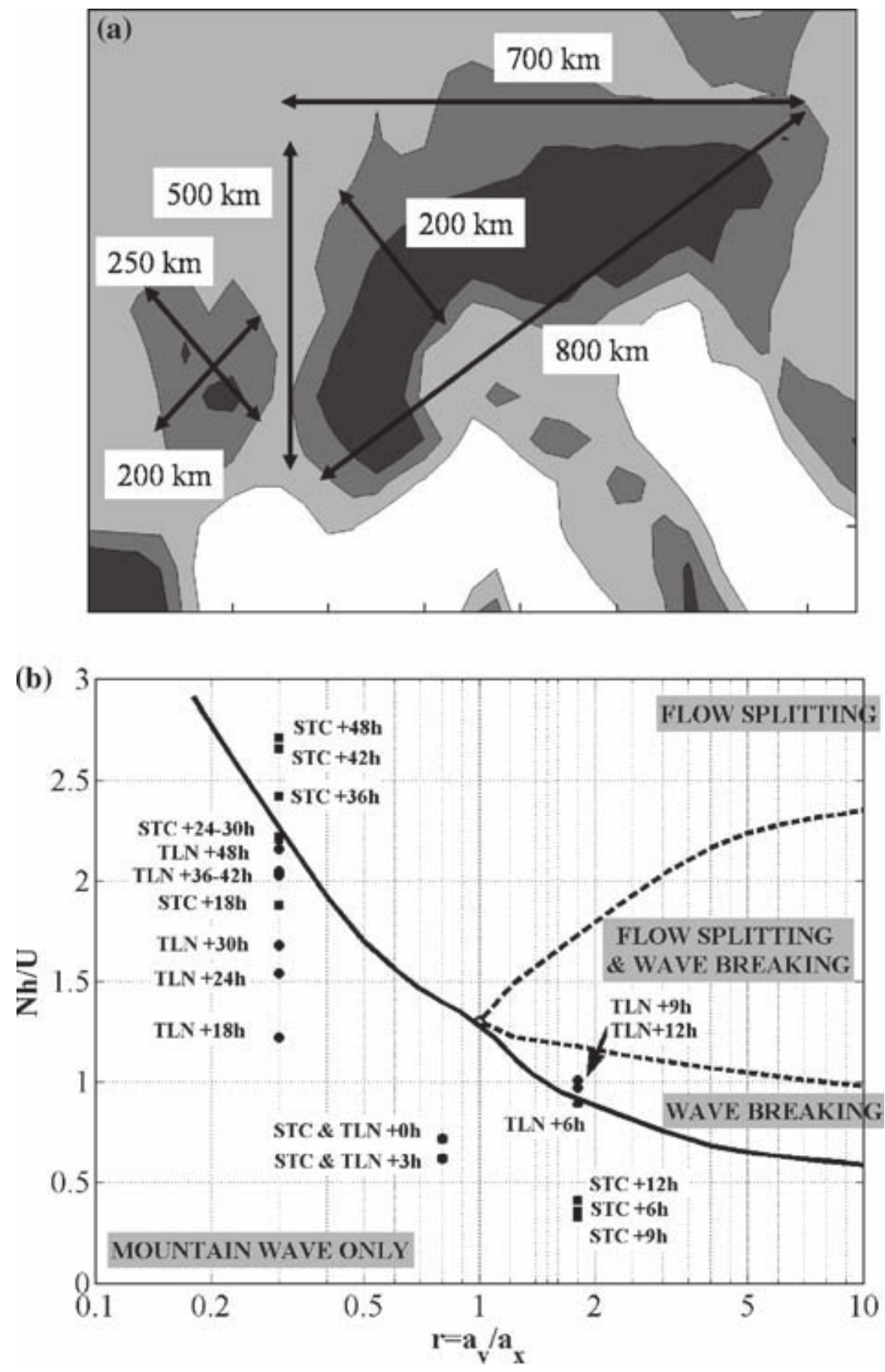

Figure 8. (a) Determination of the horizontal aspect ratio $r$ for the use of the linear theory of the Massif Central and the Alps. (b) Linear regimes for the flow at STC and TLN from the 06 to the 08 November 199912 UTC. Each point corresponds with the radio sounding launching at Lyon and is associated with the duration from the onset of the mistral that occurs on the 06 November 12 UTC to the radio sounding launching.

- the Froude number $F=U \sqrt{g^{\prime} H}$ with $U$ the incident wind speed and $g^{\prime}$ the reduced gravity given by $g^{\prime}=g \frac{\theta-\theta^{\prime}}{\theta}$, where $\theta^{\prime}$ (or $\theta$ ) is the potential temperature of the upper (or lower) layer on either sides of the thermal inversion.

The shallow water theory predicts the existence of four regimes. Regime I refers to inviscid irrotational flow with no hydraulic jumps. Regime IIa refers to a wake formation without reverse flow due to the hydraulic jump. Regime IIb indicates a wake formation with a reverse flow. Regime III indicates a wake regime due to a pierced fluid surface (with $M>1$ ). 


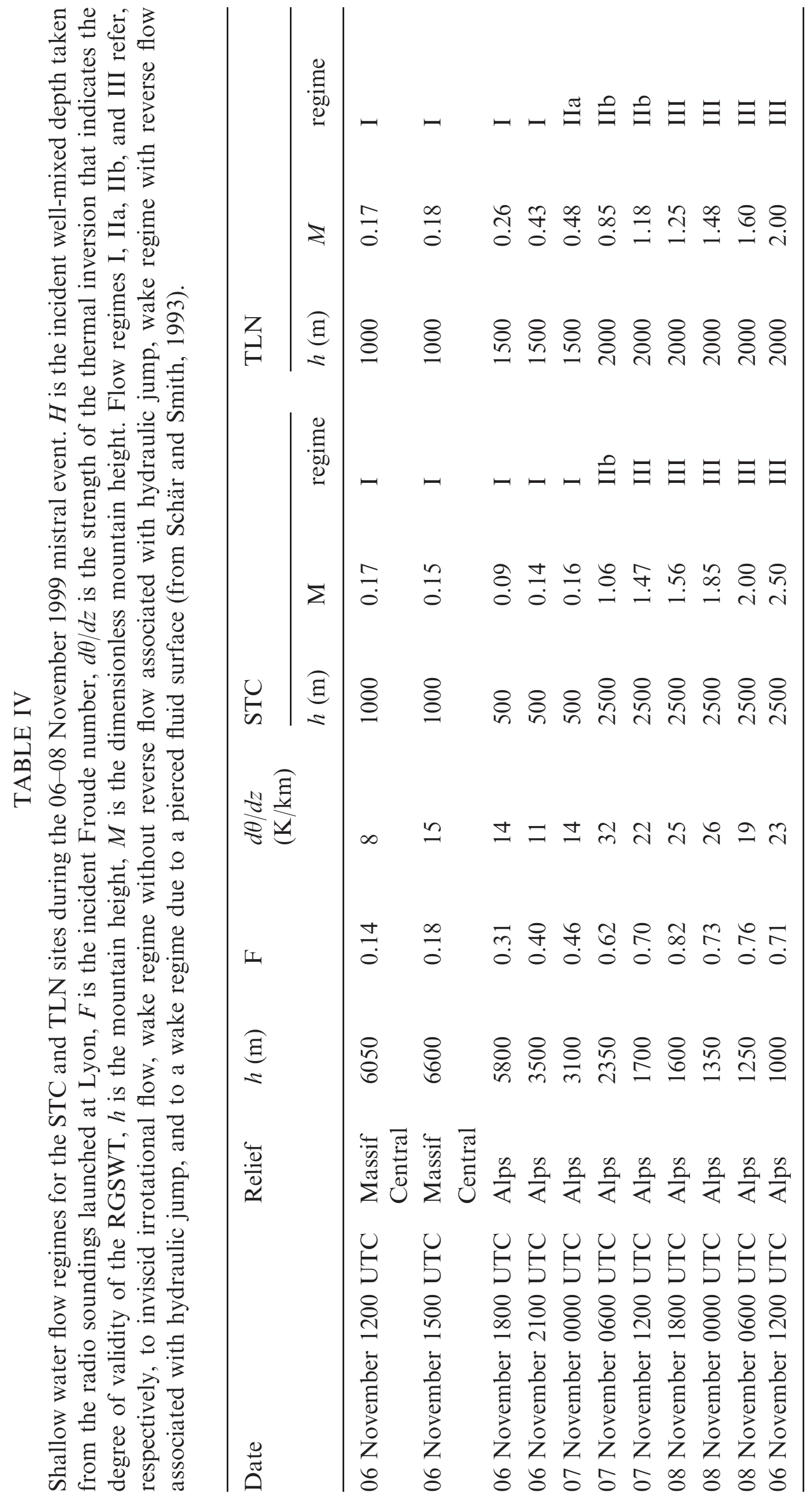


Table IV reports the values taken by the parameters $(\mathrm{M}, \mathrm{F})$ computed from the Lyon radio soundings throughout the mistral event. Figure 9 presents the shallow water flow regime for the 07 November 19990000 UTC to the 08 November 19991200 UTC. The flow is non dissipative (regime I) on 07 November 19990000 UTC above the two sites. At 0600 UTC, the shallow water theory predicts a wake regime with reverse flow (regime IIb) at the two sites. From 07 November 19991200 UTC, the theory predicts a wake regime triggered by a pierced fluid surface. As the thermal inversion is located below the mountain crest, the channelling effect upstream STC is more efficient. TLN is in the wake regime predicted by the theory that gives an explanation for the early cessation of the TLN winds (see Figure 3b). The presence of wake is confirmed by Jiang et al. (2003).

This discussion concerns the well-marked mistral situations when the whole Alps ridge is affected by a similar flow. Indeed, the conclusions made up for the MAP IOP 15 mistral event can be transposed to interpret a similar transition deep/shallow mistral that occurred from 16 to 18 June 2001.

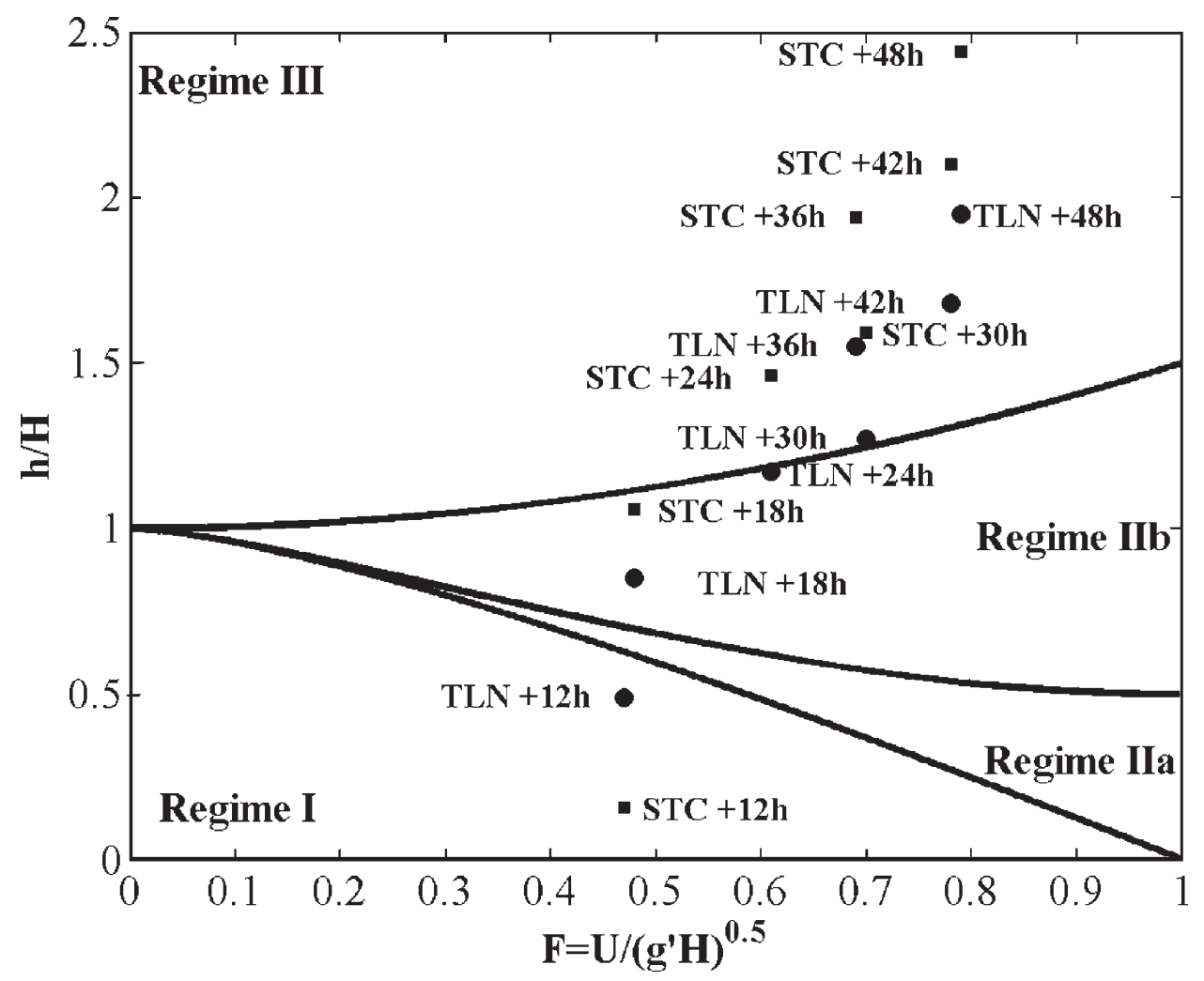

Figure 9. Shallow water flow regimes at STC and TLN from 07 November 19990000 UTC to 08 November 19991200 UTC. Each point corresponds with the radiosounding launching at Lyon and is associated with the duration from the onset of the mistral that occurs on the 06 November 1200 UTC to the radio sounding launching. 


\subsection{THE SUMMER MISTRAL}

For summer weaker mistral situations of the 21-23 June and 01 July, a linear theory analysis is carried out. However, the time resolution of the upstream conditions at Lyon is coarser (12 h).

Figure 10 presents the vertical soundings of the horizontal wind and the potential temperature at Lyon and Nîmes for the weak mistral event. For clarity of the figure and since the low-level mistral observed by the wind profilers is stronger during nighttimes, only the soundings at 0000 UTC are displayed. The incident conditions are less pronounced that the autumn event with wind speed less than $10 \mathrm{~m} \mathrm{~s}^{-1}$ below $2 \mathrm{~km} \mathrm{AGL} \mathrm{(Figure} \mathrm{10a).} \mathrm{Hence,}$ the mistral at the exit of the Rhône valley (Figure 10b) is below $15 \mathrm{~m} \mathrm{~s}^{-1}$ and looks like a LLJ as the wind profilers reveal (Figure 4). Note that the mistral at Nîmes is more intense than the mistral reported by the two wind profilers.
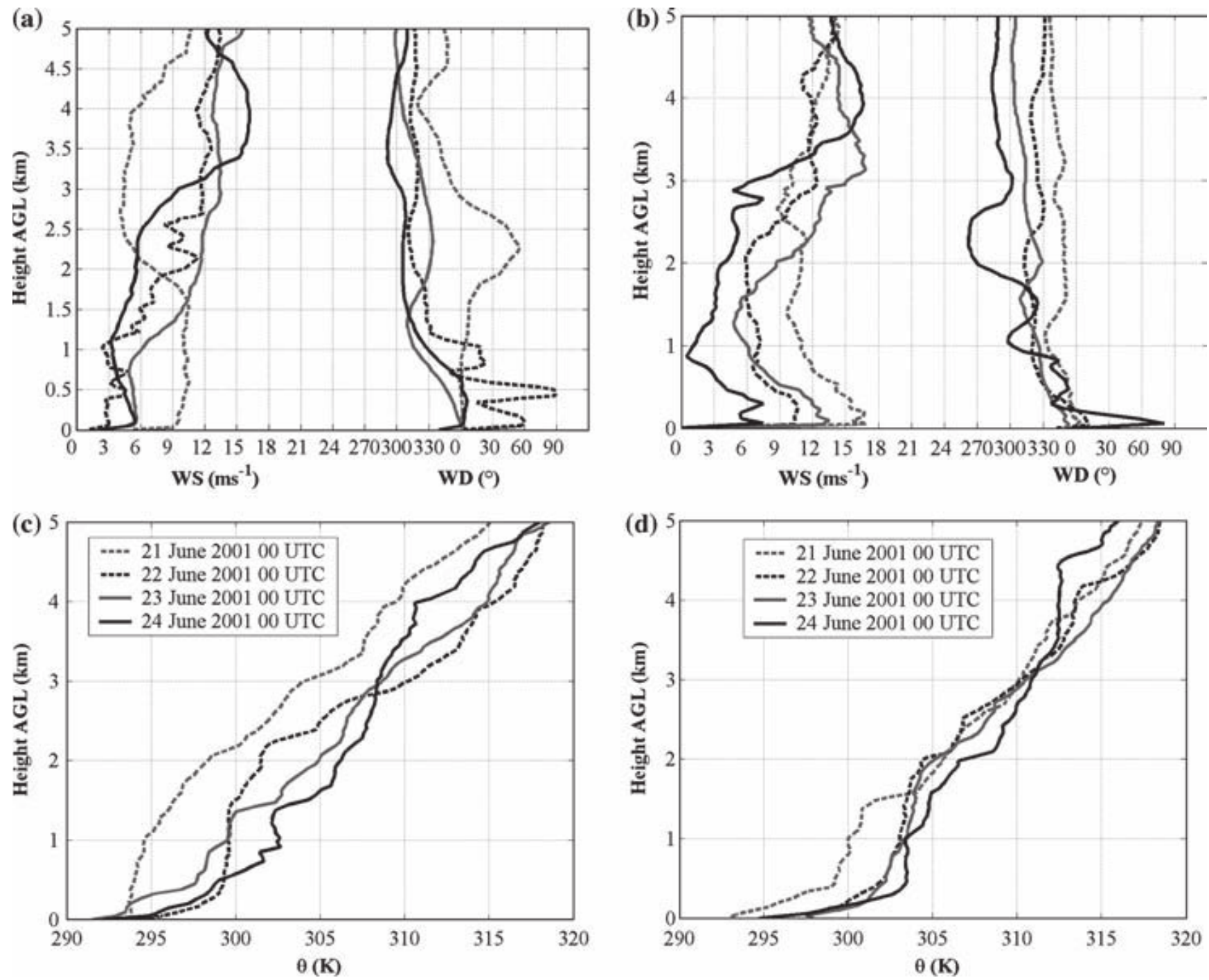

Figure 10. Vertical profiles of (a) the wind speed and direction at Lyon, (b) the wind speed and direction at Nîmes, (c) the potential temperature at Lyon and (d) the potential temperature at Nîmes on the 21 June 20010000 UTC (dashed grey line), 22 June 20010000 UTC (dashed black line), 23 June 20010000 UTC (solid grey line) and 24 June 20010000 UTC (solid black line). Wind speeds are given in $\mathrm{m} \mathrm{s}^{-1}$, wind direction in degrees and potential temperature in $\mathrm{K}$. 


\section{TABLE V}

Linear theory regime for the STC and AIX sites during the 21-23 June and 1 July mistral events, $h$ is the mountain height, $r$ is the horizontal aspect ratio, $N h / U$ is the dimensionless mountain height. The regimes are referred to MW mountain waves, WB wave breaking, FS flow splitting (from Smith, 1989).

\begin{tabular}{|c|c|c|c|c|c|}
\hline \multirow[t]{2}{*}{ Date } & \multirow[t]{2}{*}{ Relief } & \multicolumn{4}{|c|}{ STC and AIX } \\
\hline & & $h(\mathrm{~m})$ & $R$ & $N h / U$ & regime \\
\hline 21 June 0000 UTC & Alps & 500 & 1.8 & 0.4 & MW \\
\hline 21 June 1200 UTC & Alps & 500 & 1.8 & 1.2 & $\mathrm{FE}+\mathrm{WB}$ \\
\hline 22 June 0000 UTC & Alps & 2500 & 0.3 & 4.7 & $\mathrm{FS}$ \\
\hline 22 June 2100 UTC & Massif Central & 1000 & 0.8 & 1.9 & FS \\
\hline 23 June 0000 UTC & Massif Central & 1000 & 0.8 & 2.7 & FS \\
\hline 23 June 0600 UTC & Massif Central & 1000 & 0.8 & 3.6 & FS \\
\hline 24 June 1200 UTC & Alps & 500 & 1.8 & 2.2 & FS \\
\hline 30 June 1200 UTC & Massif Central & 1000 & 0.8 & 3.5 & FS \\
\hline 01 July 0000 UTC & Massif Central & 1000 & 0.8 & 0.9 & MW \\
\hline 01 July 1200 UTC & Alps & 500 & 1.8 & 0.5 & MW \\
\hline 02 July 0000 UTC & Alps & 2500 & 0.3 & 4.0 & $\mathrm{FS}$ \\
\hline
\end{tabular}

The analysis of the stratification (Figure 10b) shows that the low-level layers are continuously stratified and no well-mixed layer occurs as in autumn. Thus, only the linear theory is applied to interpret the wind data.

Table $\mathrm{V}$ gives the linear flow regime for the weak mistral event and Figure $12 \mathrm{a}$ reports the results in the linear regime. The theory generally predicts that the flow is governed by the splitting around the Alps and the Massif Central. The nocturnal LLJ observed by the wind profilers (Figure 5) likely results from the channelling by the Rhône valley. Moreover, the mistral observed at Nîmes and by a sodar set up at Avignon during ESCOMPTE located nearer the Rhône valley axis (see Figure 1 for its exact location) is $2 \mathrm{~m} \mathrm{~s}^{-1}$ stronger than the coastal mistral observed at AIX and STC. However, the theory fails to describe the wind structure changes from daytimes to nighttimes.

Firstly, as the synoptic situation is not very pronounced, the Alps is not only affected by incident northerly flow. During daytimes, the coastal mistral is affected by sea breezes and by thermally driven convection over ground, observed by various platforms of the instrumental network. These local thermal effects that are strong enough to lift up the mistral above $2 \mathrm{~km}$ AGL (Figure 4) disturb the validity of the linear theory. During nighttime, the land breeze partly accelerates the low-level mistral giving birth to a LLJ. Moreover, nocturnal radiative cooling increases the stratification in the 

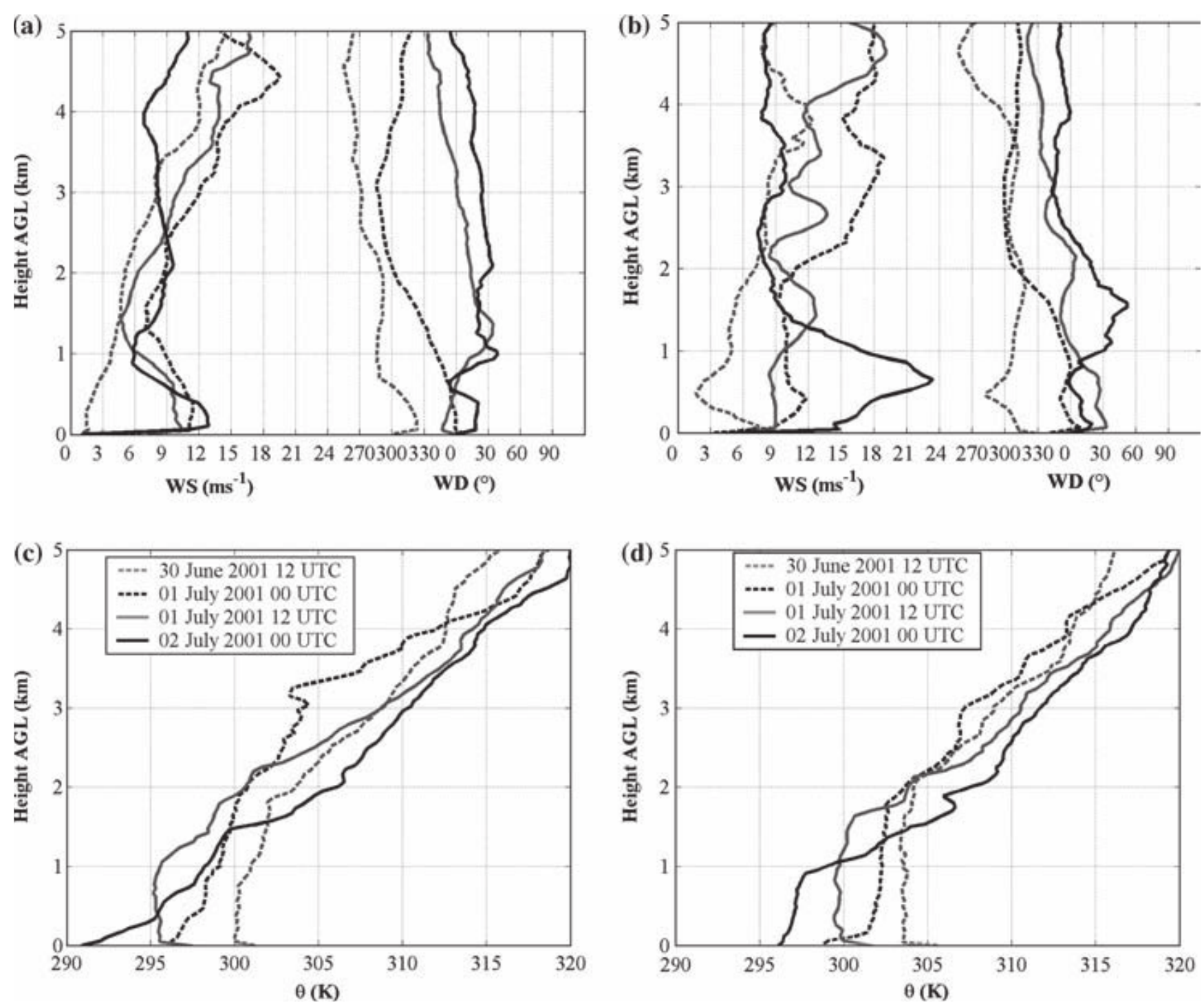

Figure 11. The same as Figure 10 on 30 June 20011200 UTC (dashed grey line), 01 July 2001 0000 UTC (dashed black line), 01 July 20011200 UTC (solid grey line) and 02 July 20010000 UTC (solid black line).

atmospheric boundary layer. It results in nocturnal summer conditions that are more similar in term of stratification with the winter conditions explaining the onset of the nocturnal LLJ. The local thermal effects are not obviously considered in the upstream conditions.

Secondly, the incident wind direction profile exhibits low-level wind shears, particularly outlined on 22 June 20010000 UTC (Figure 10b) that render difficult the computation of $N h / U$ and $r$ of the linear theory.

Linear theory can be used to interpret the moderate summer events of the 01 July. Figure 11 displays the vertical soundings of the horizontal wind and the potential temperature at Lyon and Nîmes from 30 June 1200 UTC to 02 July 0000 UTC. The mean wind speed measured at Lyon as the mistral is fully developed is around $10 \mathrm{~m} \mathrm{~s}^{-1}$ below $2 \mathrm{~km} \mathrm{AGL}$ (Figure 11a). The incident winds veer from north-westerly to north-easterly. The resulting flow observed at Nîmes experiences a marked low-level acceleration (Figure 11b) especially at 02 July 0000 UTC when the winds stop at AIX and STC (Figure 5). The analysis of the 

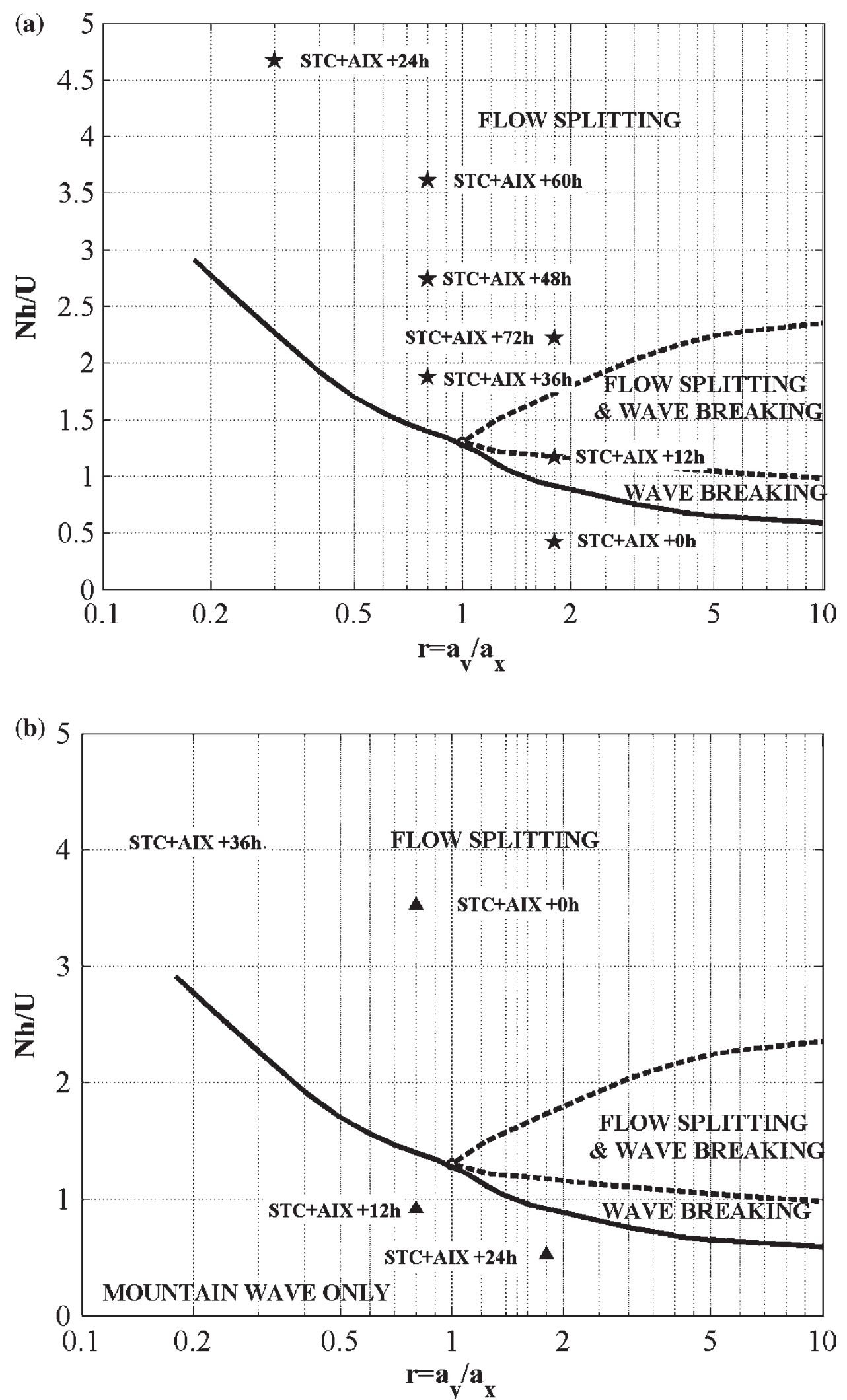

Figure 12. Linear regimes for the flow at STC and AIX for the (a) 21-23 June and (b) 01 July mistral events. Each point corresponds with the radiosounding launching at Lyon and is associated with the duration from the onset of the mistral that occurs on the (a) 21 June 0000 UTC and (b) 30 June 1200 UTC to the radio sounding launching.

potential temperature profiles (Figures 11c and d) shows that the low-level layers are less stable. The well-mixed depth of the mistral is thus clearly visible at Nîmes and gets progressively thinner with time (from 2 to $1 \mathrm{~km}$ ). 
Table $\mathrm{V}$ gives the linear flow regime for the moderate mistral event and Figure $12 \mathrm{~b}$ reports the results in the linear regime. The theory predicts a FS regime at the onset of the mistral, consistent with the weak winds below $5 \mathrm{~m} \mathrm{~s}^{-1}$ measured at Lyon. Then, the MW regime corresponds with the deep mistral structure as in the autumn case. FS is predicted at the mistral breakdown. This regime can be linked with channeling effects that trigger a LLJ at STC (Figure 5a) and at Nîmes (Figure 11a). However, the theory fails to describe the small-scale effects responsible for the differences in the wind structure of STC and AIX. For instance, the breakdown of the deep mistral at AIX is associated with a LLJ at STC. Strong variability occurs at a $30-\mathrm{km}$ horizontal scale and the weak time resolution of the vertical soundings prohibits the interpretation of the flow with the linear theory. Aircraft data obtained by the Dornier (Corsmeier et al., 2004) show that AIX is located at the limit of the eastern mistral shear line that borders the Alps wake. That feature is also observed during the 28 June 2001 mistral episode (Drobinski et al., 2004). The presence of the wake is predicted by the shallow water theory of Schär and Smith (1993) since the thermal inversion at $2 \mathrm{~km} \mathrm{AGL}$ pierces the mountain height $(2.5 \mathrm{~km})$ in a northeasterly incident flow.

\section{Summary}

This paper examines the inhomogeneity and unsteadiness aspects of the mistral LLJ dynamics using a network of UHF wind profilers that was operated during the MAP and ESCOMPTE field experiments that took place in autumn 1999 and summer 2001, respectively. Some interpretations of the observed wind structure are carried out by the use of the linear theory of Smith (1989) and the shallow water theory of Schär and Smith (1993).

Both theories show that the wind structure observed downstream the Alps and the Massif Central results from the time evolution of the upstream conditions especially when synoptic conditions are well marked. They predict that the FS process plays a major role to explain the shallow mistral at STC. The LLJ, triggered by north-easterly upstream winds, is strengthened by the channelling effect explaining the cause of its persistence. The linear theory indicates that the LLJ at TLN results from WB occurring in downslope windstorms. The loss of momentum in associated hydraulic jumps develops a wake with reverse flow explaining the early cessation of the TLN winds. Confirmations of such processes can be found in non-hydrostatic numerical simulations that highlight a tropopause foliation over the Alps during the 0607 November 1999 mistral event (Hoinka et al., 2003). Thus, the theories evidence that although the STC and TLN low-level jets look similar, their origins are very different. 
Simple theories can not be applied for weaker mistral events as local effects play a major role for the wind structure. If the mistral is weak, its LLJ structure is removed by the sea breezes and convection over heated land and lifted up above the atmospheric boundary layer. During nighttime, the summer mistral dynamics are similar to the winter dynamics linked with the advection of relative cold air embedded in the stable boundary layer. Moreover, the nocturnal summer mistral is accelerated by the land breeze. These arguments give possible explanations for its nocturnal LLJ structure.

Our study is a first step to understand the strong time and spatial variability of the mistral. Future work will focus on channelling and downslope processes with the help of the hydraulic theory. Furthermore, high resolution numerical simulations will be performed to describe the interaction between the mistral and the gravity wave activity in the lee of the Alps and the possible role of these waves on the mistral breakdown and also on the mistral/sea-breeze interactions.

\section{Acknowledgements}

The CNRS, the INSU/PATOM, Météo-France, and EDF are gratefully acknowledged for their financial and/or logistical support. The authors are also thankful for the efforts made by the number of international committees, working groups and staffs during the MAP and ESCOMPTE Special Observing Periods. Special thanks are given to Y. Pointin from the University of Clermont Ferrand for his help to retrieve the ECMWF data and to Philip Currier from the company Degréane for his work on the wind-profiler and its associated software. The anonymous referee is also gratefully acknowledged for helpful suggestions

\section{References}

Aebischer, U. and Schär, C.: 1998, 'Low-level Potential Vorticity and Cyclogenesis to the Lee of the Alps', J. Atmos. Sci. 55, 186-207.

Bleck, R. and Mattocks, C.: 1984, 'A Preliminary Analysis of the Role of the Potential Vorticity in Alpine Lee Cyclogenesis', Contrib. Atmos. Phys. 57, 357-368.

Blondin, C. and Bret, B.: 1986, 'Numerical Study of the Mistral with a Mesoscale Model', in preprint Scientific results of the Alpine experiment (ALPEX), GARP Publication Series, WMO/TD, pp. 549-563.

Bordreuil, C., Barbia, A., and Comte, P.: 1973, 'Vent du Nord Ouest à Marseille de 1882 à 1970', Monographie 88 de la Météorologie nationale.

Bougeault, P., Binder, P., Buzzi, A., Dirks, R., Houze, R., Kuettner, J., Smith, R. B., Steinacker, R., and Volkert., H.: 2001, 'The MAP Special Observing Period', Bull. Amer. Meteorol. Soc. 82, 433-462. 
Buzzi, A. and Speranza, A.: 1986, 'A Theory of Deep Cyclogenesis in the Lee of the Alps. Part I: Modifications of Baroclinic Instability by Localized Topography', J. Atmos. Sci. 42, $1521-1535$.

Buzzi, A. and Tibaldi, A.: 1978, 'Cyclogenesis in the Lee of the Alps: A Case Study', Quart. J. Roy. Meteorol. Soc. 104, 271-287.

Corsmeier, U., Behrendt, R., Drobinski, P., and Kottmeier, C.: 2004, 'The Mistral and its Effect on Air Pollution Transport and Vertical Mixing', Atmos. Res., in press.

Cros, B., Durand, P., Cachier, H., Drobinski, P., Fréjafon, E., Kottmeier, C., Perros, P. E., Peuch, V. H., Ponche, J. L., Robin, D., Sa, F., Toupance, G., and Wortham, H.: 2004, 'The ESCOMPTE Program: An Overview', Atmos. Res. 69, 241-279.

Drobinski, P., Dusek, J., and Flamant, C.: 2001a, 'Diagnostics of Hydraulic Jump and Gap Flow in Stratified Flows over Topography', Boundary-Layer Meteorol. 98, 475-495.

Drobinski, P., Flamant, C., Dusek, J., Flamant, P. H., and Pelon, J.: 2001b, 'Observational Evidence and Modelling of an Internal Hydraulic Jump at the Atmospheric Boundarylayer Top during a Tramontane Event', Boundary-Layer Meteorol. 98, 497-515.

Durran, D.: 1986, 'Another Look at Downslope Windstorms. Part I: The Development of Analogs to Supercritical Flow in an Infinitely Deep, Continuously Stratified Fluid', $J$. Atmos. Sci. 93, 2527-2543.

Egger, J.: 1972, 'Numerical Experiments on the Cyclogenesis in the Gulf of Genoa', Contrib. Atmos. Phys. 45, 320-346.

Egger, J.: 1988, 'Alpine Lee Cyclogenesis: Verification of Theories', J. Atmos. Sci. 45, 2187-2203. Flamant, C.: 2003, 'Alpine lee Cyclogenesis Influence on Air-Sea Heat Exchanges and Marine Atmospheric Boundary Layer Thermodynamics over the Western Mediterranean during a Tramontane/Mistral Event', J. Geophys. Res. 108(C3), 8057, 1029/2001JC001040.

Georgelin, M. and Richard, E.: 1996, 'Numerical Simulation of Flow Diversion around the Pyrenees: A Tramontana Case Study', Mon. Wea. Rev. 124, 687-700.

Hoinka, K. P., Hagen, M., Volkert, H., and Heimann, D.: 1990, 'On the Influence of the Alps on a Cold Front', Tellus 42A, 140-164.

Hoinka, K. P., Richard, E., Poberaj, G., Busen, R., Caccia, J. L., Fix, A., and Mannsetein, H.: 2003, 'Analysis of a Potential Vorticity Streamer Crossing the Alps during MAP IOP-15 on 6 November 1999', Quart. J. Roy. Meteorol. Soc. 129, 588, 609-632.

Jiang, Q., Smith, R. B., and Doyle, J. D.: 2003, 'The Nature of the Mistral: Observations and Modelling of Two MAP Events', Quart. J. Roy. Meteorol. Soc. 129, 857-876.

Long, R. R.: 1953, 'Some Aspects of the Flow of Stratified Fluids: I. A Theoretical Investigation', Tellus 5, 42-58.

Mayençon, R.: 1982, Météorologie Pratique, Editions Maritimes D’Outre-Mer, 336 pp.

Millot, C.: 1979, 'Wind Induced Upwellings in the Gulf of Lions', Oceanol. Acta 2, 261-274. Orieux, A. and Pouget, E.: 1984, 'Le mistral: Contribution à l'étude de ses aspects synoptiques et régionaux', Monographie 5 de la Météorologie nationale.

Pettré, P.: 1982, 'On the Problem of Violent Valley Winds', J. Atmos. Sci. 39, 542-554.

Rhein, M.: 1995, 'Deep Water Formation in the Western Mediterranean', J. Geophys. Res. 10(C4), 6943-6959.

Schär, C. and Smith, R. B.: 1993, 'Shallow-Water Flow Past Isolated Topography. Part I: Vorticity Production and Wave Formation', J. Atmos. Sci. 50, 1373-1400.

Smith, R. B.: 1985, 'On Severe Downslope Winds', J. Atmos. Sci. 42, 23, 2597-2603.

Smith, R. B.:1989, 'Hydrostatic flow over Mountains', Advances in Geophysics, Vol. 31, Academic Press, 1-41.

Smolarkievicz, P. K. and Rotunno, R.: 1989, 'Low Froude Number Flow Past Three Dimensional Obstacles. Part I: Baroclinically Generated Lee Vortices', J. Atmos. Sci. 46, $1154-1164$. 
Sprenger, M. and Schär, C.: 2001, 'Rotational Aspects of Stratified Gap Flows and Shallow Foehn', Quart. J. Roy. Meteorol. Soc. 127, 161-188.

Tafferner, A. and Egger, J.: 1990, 'Test of Theories of Lee Cyclogenesis: ALPEX Cases', J. Atmos. Sci. 47, 2417-2428.

Wrathall, J. E.: 1985, 'The Mistral and Forest Fires in Provence-Côte d'Azur-South France', Weather 40, 119-124. 